\title{
The Rights of Ethno-Cultural or Political Minorities and Development in Nigeria
}

\author{
David Aondoakaa Utume Iveren Adoo Uganden* \\ Department of Political Science, Benue State University, PMB 1021119, Makurdi, Nigeria
}

\begin{abstract}
In Nigeria, the concept of minority has been misconceived and misapplied. The colonialist classificatory scheme of identifying cultural or ethnic minorities and majorities has been excessively adhered to and politicized. This has produced politics of exclusion and the concomitant denial of rights, especially to groups considered political minorities. This can be couched as the 'minoritazation' of cultural, ethnic or even locational groups. In Nigeria, such politics of marginalization translates to exclusion from participation of human resources that cannot be ignored in the development agenda of the country. To reposition these minorities, a constitutional review aimed at restructuring power relations in the country needs to be undertaken. Any honest desire for development of Nigeria must cultivate the courage to undertake this politico-social engineering such as other countries like India have successfully done. This paper establishes a strong connection between the rights of ethno-cultural and political minorities and development in Nigeria through an empirical cataloguing of contribution of minorities to the political process in Nigeria.
\end{abstract}

Keywords: Ethnic minorities, National development, Political minorities, Political participation, Political exclusion

DOI: $10.7176 / \mathrm{DCS} / 10-6-02$

Publication date: June $30^{\text {th }} 2020$

\section{Introduction}

In the contemporary world, the most cherished value over which people spend a lot of energies trying to secure or trying to protect is rights. Rights, if denied, could amount to disempowerment. Denial of rights amounts to denial of space to participate in affairs of the community where one belongs. Experience has shown that minorities are most susceptible to losing their rights in a political set up. Losing of such rights amounts to blocking the space of participation in any development effort. The withdrawal of participation also means that such energies, knowledge and skills of such a minority are no longer channelled towards contributing to development efforts. It is ironical that the state system bequeathed by the colonialist engendered the politics of exclusion rather than inclusion. Dependence on political parties as the basis for recruitment of leaders is the very practice of the politics of exclusion. Indeed, multi- party advocacy became equated with democracy. Painstaking effort was not exerted in questioning the basis on which political parties should operate in a given polity. Thus, 'multi-partism', before it could bring about the room for political participation in Nigeria, became thoroughly abused. First, it encouraged ethnic politics by becoming a reason for fissiparous associations based on ethnicity. Second, there was multiplicity of groups without good political reason. This situation still obtains in present-day Nigeria, where there are more than eighty (80) political parties without any ideological differences between them. Party formation, a practice in political exclusion, conceals under it more serious practices of exclusion which is the denial of rights. This very denial of rights through ethnicity (Nnoli, 1980) has then led to avoidable strife. Indeed, the Nigerian civil war is explained by some (Young, 1979, P.18) on the basis of ethnic sentiments. It cannot be denied that certain discriminatory practices that lead to marginalization of individual groups provide the rationale behind the sentiments. That the Willink commission took the minority agitations seriously suggests that there were good reasons for a constitutional security for these minorities.

Without further question, this paper assumes that the minority question has not been resolved. This is in view of the fact that state creation as advocated by groups like the United Middle Belt Congress (UMBC) and the Calabar, Ogoja, Rivers Movement and the Mid-West Movement has not taken care of minority dissatisfaction. A new look can be taken at minority agitations especially the fact of the evolution of the concept since 'minority' is acquiring new dimensions. As cultural groups, numerical majorities can be turned into political minorities. This is "minoritazation" of numerical majorities. The Ba Tutsi and the Ba-Hutu case in Rwanda is to the point. Geolocational marginalization can be included into such a rendering of certain places 'minoritized'. In Nigeria, we can talk of the coastal regions (as majority locations) and the hinterland (as minority region). But most intriguing and unspoken case is the case of Nigeria West of the Niger (majority) and Nigeria East of the Niger (minority). The geo-locational equation is that the favoured locations enjoy the majority rights while the un-favoured suffer denial of such rights, numerical strength not-withstanding.

\section{Understanding the concepts of Minority and Development}

The two concepts are treated separately and distinctively to avoid confusion. How they connect is a matter for later 
discussion. So, under here, we are not yet involved with understanding how minority connects to development.

\subsection{Minority}

This more or less statistical expression was hardly a theoretical matter, indeed it remains so unless taken as part of the pluralist argument. From that perspective of groups, even ethno-cultural, are classified into majority and minority. The politics of how these groups, majority, are reckoned with becomes significant. The minorities tend to suffer more deprivation when it comes to accessing the social or political rights. Often, the state has acted as the distributor of such privileges or rights. In the new states, especially of Asia, ethnic identity was actively used or created to serve administration. According to Meredith (1997, p.154),

At the outset of colonial rule, administrators and ethnographers endeavoured to classify the people of Africa, sorting them out into what they called tribes, producing a whole new ethnic map to show the frontiers of each other.

When it comes to privileges, they were given according to majority before the minorities. The abuse of this cultural status (majority and minority) became more annoying as applied by the colonialists. It has been observed that the greatest culprit in this abuse was the colonial administrator. "His abuse manifested in resource allocation and distribution of privileges" (Utume, 2013, p.82).

Over the years, and especially in the new states of Africa, and perhaps Asia and Latin America, minority status has come to be identified with deprivation, denial of rights to such a group. In Africa, there is this tendency to render even numerical majorities inferior in terms of privileged distribution or in accessing of rights. For a long time, this situation obtained in Rwanda where the Tutsi minority enjoyed all the privileges of the state at the expense of the majority Hutu. This, as earlier observed was minorization of the Hutu. Ditto, apartheid South Africa where the numerical minority, (the whites), were "majorized" in the allocation of resources and privileges. This is no tutorial issue, more so that the space in political participation has often shrunk rather than expanded. Democracy which should open it up is hardly forth-coming. Thus so long as such deprivation and privileges define the nature of the relation between groups, so long shall the minority question become nagging to the national psyche.

When situations like what we have attempted to describe obtain, the fear of domination, as it were, becomes a troubling one. Sometimes the distinctions are not necessarily cultural or ethnic. In Nigeria, that the majority Westernized South played a main role in how the country responded to the issue of independence (Crowder, 1978), is illustrative. Ironically, this problem of the privileged majority and a dominated deprived group, especially cultural, manifested in the regions themselves. It was also expected that it would be resolved after the Willink Commission report, even before self-rule would be given to Nigeria. It did not resolve it. So far, the minority fears have not been allayed despite the further creation of states out of the three regions. They have not enjoyed the rights they looked forward to enjoying in Nigeria's effort at development.

\subsection{Development}

There are those who may feel that the debate about what is development is not yet closed. In 1994, in a faculty seminar, (Utume, 1994) drew the faculty's attention to the fact that many scholars are seeing alternative paths to development besides Westernization or modernization. Indeed, Verhelst (1990) insisted that because non-Western cultures had their notions of economy, and development, they should search for their development in their roots. In the same seminar, it was suggested that modern Africa might start this journey in the persistence of African heritage (Utume, 2015). However, pointing to such alternative paths alone did not define development and this prompts the need to offer what may be considered the true meaning of development.

Development has two ends to it- the physical and social. The most critical, however, is the social. This is because the social is made of the human activity that can transform the physical to achieve what man desires. This means man's exploitation of the physical environment with all its endowments to serve his well-being. This much is what explanation Rodney (1972) offered. Concisely, this is about qualitative growth or expansion. We need to also add that development in this sense is a collective affair. Thus the expression social development or national development is conceptualized. Such realities modify the concept of development. This viewpoint contradicts the pure growth notion of development. Of course, in as much as growth alone does not qualify development, we cannot exclude it from conceptualizing development. In sum, this acknowledgement is worth nothing:

Indeed the movement for development embodies a value judgment with which few would disagree, the desirability of overcoming malnutrition, poverty and disease which are the most immediate and widespread aspects of human suffering. In positive terms some advocate a commitment to development that transcends the limiting terms of economic growth to embrace such features of justice as quality of opportunity, full employment, generally available social services, equitable distribution of income and basic political freedoms. (Berstein, 1973, pp 1314)

From the foregoing, it is clear that development is not an easy concept to capture even for what it is without the personal distortions that individual sentiments bring to hear. But it appears to have overcome such subjective 
connotations as were initially brought to bear on its meaning.

\section{Minority rights and Development}

National development as a collective endeavour presupposes that it is better achieved through an inclusive social arrangement. Efforts should not be spared, so the energies of every member of the community. Of course, it connotes participatory involvement of all. Any measure of exclusion becomes detraction from that collective effort. To talk of minority rights is to enter the debate on the positives of pluralism. This is, to the extent to which a group, here, minority group, is allowed participation; to that extent would it be available for mobilization towards national development programmes and goals. Kwanashie (1997) has observed that ethnic groups, especially in the developing countries, are wont to base their development programme along the lines of identity groups.

In virtually all developing societies, it has been observed that a regular pattern of collective action in the quest for material advancement within states has been along identity patterns. In fact, it has been the struggle for the advancement of material condition of groups and sub-groups within the state that has been influenced by ethnic on communal relations (Kwanashie, 1997, p. 245

It is clear from the foregoing that groups, including minorities, are important to the planning and mobilization towards national development. But such mobilization is only feasible if the group (minority in this case) enjoys the rights of participation, individually or collectively. Nkom (1997) has closely associated culture with development. He draws scholars' and policymakers' attention therefore to 'the danger of treating culture and economic development as if they were separate and unrelated spheres in the overall struggle for economic development and national transformation" (Nkom, 1997, p.232). It is the thesis he has argued through his chapter of the book. It needs to be further explained how it connects to our purpose. To talk of culture is to talk of identity groups. These may be ethnic nationalities. This directly brings minority into the argument. Minority rights anticipate the mobilization of such groups whose energies are needed at the point of planning for national programmes. We do not have all the time and space to provide greater details, but we hasten to add that countries that aspire to achieve higher development adopt integration policies which entail removing as much as possible, hindrances to group rights. These include minority rights.

Young (1976) has been anxious to compare and discover similarities between Nigerian and Indian plural complexity. He went on to consider that these might achieve relative integration in their cultural diversity. He may be right in his optimism with the Indian case. He is very wrong in the case of Nigeria. For whereas India has been able to remove obstacles to group rights, Nigeria seems to be sinking deeper into the abyss of disunity despite the structural arrangement in the federation. For, India, the contrast with Nigeria is outstanding. Bahsin (1997) has given an account of the Indian experience with cultural diversity and how she has overcome the differences to achieve social integration and so develop. According to him, India achieved such integration through the clear vision of the national leaders who won independence from the British. They gave India the constitution that Indians desired.

As a secular democracy, the constitution-assuring the dignity of individual and the unity of the nationconstitutes the essence of these aspirations which brought together a vast multitude of humanity comprising diverse cultures, languages, religions and economic levels of living. Taking special care of the vulnerable and the weaker sections, the constitution propounds a set of guarantees of human rights and principles of state policy which embody the ends and means of the Indian vision (Bhasin, 1997, p.134). A country that is faithful to the rules and the means of securing such rights as India has done, will normally give confidence to all groups. They will be available for mobilization towards the national cause of development. It follows logically, that where the country does not secure the rights of its groups, development will be hard to achieve on account of unavailability of their energies and contributions.

\section{Minority Rights and Development in Nigeria}

According to Young (1979, p.276), "ethnicity, languages, region and religion interactively form Nigeria's matrix of pluralism". Different cultural groups, indeed ethnic nationalities, make up this matrix including minorities. What has Nigeria's experience been, especially with minorities?

As far as ethnic politics is concerned, (Nnoli, 1980), Nigeria is yet to be surpassed. For here, his point on the place of ethnic minorities is worth noting. First, apparent discrimination against them and fear of marginalization caused the response of the minorities. This statement captures it. The increasing rallying of each major ethnic group behind a political party, and the emphasis placed by Nigerian politicians on the pursuit of ethnic interest, raised fears among the leaders of the minority groups concerning neglect and domination by leaders of the major groups (Nnoli, 1980, p. 169). Second, inter-regional competition among the so-called ethnic majorities served not as examples to follow but was urged on by such ethnic majorities from other regions. It was part of the interregional competition.

This meant that the relative integration standard at the regional level, such as the Northernization of the North 
or pan-Yoruba solidarity in the Western region (Young, 1979), pp. 276-281) would soon crumble in the face of such political awareness among the minorities of the regions. In the Eastern region, where no such effort occurred by way of incorporating the minorities, the break up was snappy and swift between the geo-political leaders and the Azikwe's quarrel with Eyo Ita was quickly and easily turned into an Igbo-Efik standoff (Nnoli, 1980, pp. 1689). In the North, politicisation of minority agitations is captured in the formation of the United Middle Belt Congress (UMBC) and its agenda, the creation of a Middle Belt region. By extension, its view of the Nigerian Federation was in tandem with that of the National Independence Party (NIP). But, if we must take the issue of a balanced federation as a more principled stand to secure all people's interest, the noble request had to be sacrificed on the altar of grand ethnic politics. The creation of the Mid-West region out of Western Nigeria in 1963 was most hypocritical. It was solely aimed at breaking up the base of the Action Group (AG). The Northern Region should have been the foremost candidate for dismemberment if there was any noble intention. Even the Eastern Region was sufficiently qualified to undergo such a surgery. It did not. That meant that the two members of the national coalition government of the Federation, Northern People's Congress (NPC) and National Council of Nigerian Citizen (NCNC) were unscathed in the so-called act of balancing the federation. It was clearly a case of political mischief.

The minority agitations, avoided solution in the Willink Commission of 1957, subsisted till 1967 when the civil war imposed another challenge of restructuring the federation. The twelve states structure imposed by the military administration in 1967 was also dishonest, though tactically sound for the containment of the Igbo Biafran scheme. It isolated them in the East Central state of the new federation. Indeed the minority grouse was not put in the front burner in this exercise. Since then, we have acquired a thirty-six states structure including a Federal Capital Territory, with our bag-full of minority complaints still subsisting.

Restructuring and so balancing the federation was to secure the rights of all, but especially those of the minorities. It was not achieved in all the state creation exercises. It is one of the constitutional opportunities lost. Another area of failure, compared with India (Bahsin, 1997) has been the attitude to the constitutional provision for securing the rights of the citizens. The Nigerian constitution is indeed over-written. It attempts to cover every aspect of national life. Indeed, the best of its provisions are the fundamental objectives and directive principles of state policy. Again, in typical Nigerian hypocrisy to the protection of citizen rights, these are not justiceable. Leaders are not encouraged to defend these, neither are they dissuaded from abusing them. Nigerians are left to the whims and caprices of their leaders.

As noted by Kwanashie (1997), when it comes to the distribution of resources and privileges, the minorities become the worse off for it. Moreover, leaders are by this act of disregard for the people as demonstrated in the constitution, left to their schemes. Public treasuries in Nigeria are now looted with reckless abandon. It all started with the rulership of General Ibrahim Babangida. It was in his reign that executive allowances were no longer accounted for in Nigeria. Public officers could now draw any amount from the public treasury, but for which they were not to give any account. Thus, from cabinet members to all public servants the morsel of office became juicier. This signalled the death of merit in holding public office and it sowed the seed of impunity. Those appointed were seen as given their share of the national cake, as one had to be reckoned with to get such an office. The minorities are held at the receiving end of this short stick. To further seal the reign of public misdemeanour, Babangida introduced Structural Adjustment Programme (SAP). It introduced a national culture that threw overboard any ethics in public service. This was the era in which every public officer especially military in high places was a bank owner. These banks bought dollars cheap from the Central Bank of Nigeria (CBN) and sold them high at the foreign exchange markets. It caused the run on the Naira, besides increasing Nigeria's debt burden. The loans obtained under SAP attached especially high interest rates. This is where irrational or at best selfish politics and poor governance has taken the Nigerian nation. The minority has lost his rights of participation, and even of voicing out under the circumstances. He has been effectively marginalized, nay excluded.

With the coming of the Fourth Republic, another aspect of this behaviour has been born. It is the culture of impunity. Rigging into public offices has become common. Ordinary Nigerians have lost confidence in the institutions of governance, starting with the Independent National Electoral Commission (INEC). Moreover, whoever rigs in an election is likely to lead a government that is illegitimate; he can hardly call on honest Nigerians to help in the task of governance, except those as roguish as himself. For the highly educated, even the idea of the state is sneered at. They become indifferent to public affairs including elections (Utume and Shima, 2012). This intellectual aloofness alienates the group which becomes excluded from Nigeria's public affairs. The group becomes "minoritized". The point of blocking minority participation and so excluding them from the process of national development is thus established. A kind of "minoritoization" is contrived to worsen the case of minority exclusion. For example, through-out the administration of Goodluck Jonathan, the Tiv, traditionally reckoned to be the fifth largest ethnic group in Nigeria were systematically excluded from certain positions. A glaring case is the twenty-six man committee constituted to advice Jonathan. No Tiv man was represented on it. Perhaps some other groups have suffered such "minoritazation" in Nigeria. This damages the development efforts of Nigeria.

In January 2014, an Ethnic Nationalities Movement (EMM) was announced. It called for an ethnic 
Nationalities National Conference for $11^{\text {th }}$ and $12^{\text {th }}$ February in Abuja. What was interesting about the document it published was the listing of three hundred and eighty-nine (389) ethnic nationalities. Of this number, only the Fulani, Hausa, Igbo and Yoruba have been held to be majority ethnic groups. That means the remaining three hundred and eighty five (385) have been treated as minorities. The impression cannot be mistaken that a good number of the Nigerian population is excluded from mainstream public affairs of Nigeria. And the concept of minority itself becomes questionable as it verges on irrationality. This is because between majority and minority ethnics there is no threshold.

Table 1 in this write-up attempts to capture the figures by reducing the states' classification into majority, minority and mixed populations. The original three regions of Nigeria are used to classify the majority ethnic groups, the East for Igbo, North for Hausa-Fulani and the West for Yoruba, Kwara State is included here as Yoruba. The remaining states are classified into minority and mixed. The FCT and Lagos are classified as mixed because as political and commercial headquarters respectively, they are not exclusive to Gbagyi (Gwari) or Yoruba.

Table 1. State classification according to dominant ethnic nationalities of Nigeria using census figures of 2006

\begin{tabular}{|c|c|c|}
\hline Classification & Population & Total \\
\hline A Hausa/Fulani & & \\
\hline Jigawa & $4,348,649$ & \\
\hline Kano & $9,383,682$ & \\
\hline Katsina & $5,792,578$ & \\
\hline Sokoto & $3,696,999$ & \\
\hline Zamfara & $3,259,846$ & $26,481,754$ \\
\hline $\begin{array}{ll}\text { B } & \text { Igbo } \\
\end{array}$ & & \\
\hline Abia & 2833999 & \\
\hline Anambra & 4182032 & \\
\hline Ebonyi & 2173501 & \\
\hline Enugu & 3257298 & \\
\hline Imo & 3934899 & $16,381,729$ \\
\hline C $\quad$ Yoruba & & \\
\hline Ekiti & 2384212 & \\
\hline Kwara & 2371089 & \\
\hline Ogun & 3728098 & \\
\hline Ondo & 3441024 & \\
\hline Osun & 3423535 & \\
\hline Oyo & 5591589 & 20,939, 547 \\
\hline $\begin{array}{ll} & \text { Minority } \\
\end{array}$ & & \\
\hline Akwa-Ibom & 3920208 & \\
\hline Bayelsa & $1,703,358$ & \\
\hline Benue & $4,219,244$ & \\
\hline Borno & $4,151,193$ & \\
\hline Cross River & $2,888,966$ & \\
\hline Delta & $4,098,391$ & \\
\hline Edo & $3,218,332$ & \\
\hline Kogi & $3,278,487$ & \\
\hline Nasarawa & $1,863,275$ & \\
\hline Niger & $3,950,249$ & \\
\hline Plateau & $3,178,172$ & \\
\hline Rivers & $5,185,400$ & \\
\hline Taraba & 2,300736 & \\
\hline Yobe & $2,321,591$ & $46,278,142$ \\
\hline E $\quad$ Mixed & & \\
\hline Adamawa & $3,168,101$ & \\
\hline Bauchi & $4,676,465$ & \\
\hline FCT & $1,405,201$ & \\
\hline Gombe & $2,353,879$ & \\
\hline Kaduna & $6,066,562$ & \\
\hline Kebbi & $2,238,628$ & \\
\hline Lagos & $9,013,534$ & 29,922,370 \\
\hline Grand Total & & $140,003,542$ \\
\hline
\end{tabular}

Source: Extractions from the Annual Abstract of Statistics, 2008, Published by the Federal Republic of Nigeria. 
Some statements of clarification need to be made about the classificatory scheme in table 1. First, it is admissible that Hausa/Fulani is not a name for a group; it is forged to account for the two distinctive nationalities of Fulani and Hausa who happen to be found in the same location of the far north, Nigeria. It is an expression of convenience. It might also be observed that what has transpired between the two cultural groups is interesting sociologically. The two have achieved a peculiar case of acculturation, where the Fulani have succeeded to impose their rule over the Hausa, but the latter have succeeded in imposing a cultural identity over the Fulani, not only by their mode of dressing but especially in their language.

By the classification in Table 1, no single ethnic group is comparable to the so called minorities if put together. Indeed, the so-called majority are individually minorities to the rest of the Nigerian population. On the other hand, to marginalize 46,278,142 Nigerians in the name of minority politics is to do damage to Nigeria's human resources. This is to say that more than one third of the 140,003,542 total is not participating in Nigeria's development effort. It is no wonder that Nigeria has had a poor record regarding development. On the other hand, India which started at the same level with Nigeria has overcome ethnicity and other cultural complexities to advance as much as she has (Bahsin, 1997).

Table 2 Results of Nigeria's Presidential Elections 1999-2019

\begin{tabular}{|c|c|c|c|c|c|c|}
\hline Classsification & 1999 & 2003 & 2007 & 2011 & 2015 & 2019 \\
\hline \multicolumn{7}{|c|}{ A Hausa/Fulani } \\
\hline Jigawa & 548,596 & $1,101,909$ & N/A & $1,140,766$ & $1,037,564$ & $1,106,244$ \\
\hline Kano & 904,713 & $2,172,182$ & N/A & $2,673,228$ & $2,128,821$ & $1,891,134$ \\
\hline Katsina & $1,193,397$ & $1,653,161$ & N/A & $1,639,532$ & $1,449,426$ & $1,555,473$ \\
\hline Sokoto & 354,427 & 929,085 & N/A & 909,808 & 834,259 & 871,891 \\
\hline Zamfara & 380,079 & $1,053,851$ & N/A & 942,679 & 761,022 & 578,439 \\
\hline Total & $3,381,212$ & $6,910,188$ & & $7,306,013$ & $6,211,092$ & $6,003,181$ \\
\hline \multicolumn{7}{|l|}{ B Igbo } \\
\hline Abia & 535,918 & 748,034 & N/A & $1,188,333$ & 392,045 & 323,291 \\
\hline Anambra & 833,278 & 862,193 & N/A & $1,157,239$ & 688,584 & 605,734 \\
\hline Ebonyi & 345,921 & 796,626 & N/A & 502,890 & 363,888 & 359,131 \\
\hline Enugu & 835,586 & $1,126,945$ & N/A & 814,009 & 573,173 & 421,014 \\
\hline Imo & 736,306 & $1,016,481$ & N/A & $1,409,850$ & 702,954 & 511,586 \\
\hline Total & 3,287,009 & $4,550,279$ & & $5,072,321$ & $2,720,644$ & $2,220,756$ \\
\hline \multicolumn{7}{|l|}{ C Yoruba } \\
\hline Ekiti & 713,690 & 325,881 & N/A & 261,858 & 300,691 & 381,132 \\
\hline Kwara & 659,598 & 574,369 & N/A & 414,754 & 440,080 & 459,676 \\
\hline Ogun & 475,904 & $1,361,251$ & N/A & 543,715 & 533,172 & 564,256 \\
\hline Ondo & 801,797 & 888,863 & N/A & 486,837 & 561,056 & 555,994 \\
\hline Osun & 854,639 & 611,593 & N/A & 512,714 & 642,615 & 714,682 \\
\hline Оуо & 921,178 & 882,5071 & N/A & 863,544 & 881,352 & 836,531 \\
\hline Total & $4,426,806$ & $4,644,528$ & & $3,083,422$ & $3,358,966$ & $3,512,271$ \\
\hline \multicolumn{7}{|l|}{ D $\quad$ Minority } \\
\hline Akwa-Ibom & 883,278 & $1,292,395$ & N/A & $1,232,395$ & $1,017,064$ & 578,775 \\
\hline Bayelsa & 610,032 & 738,165 & N/A & 506,693 & 367,067 & 321,767 \\
\hline Benue & $1,252,957$ & $1,213,843$. & N/A & $1,047,709$ & 683,264 & 728,912 \\
\hline Borno & 915,975 & $1,120,152$ & N/A & $1,177,646$ & 501,920 & 919,786 \\
\hline Cross River & 876,156 & $1,233,321$ & N/A & 726,341 & 450,514 & 421,901 \\
\hline Delta & 816,574 & $1,142,622$ & N/A & $1,410,379$ & $1,267,773$ & 829,762 \\
\hline Edo & 679,784 & $1,106,812$ & N/A & 621,192 & 500,451 & 560,711 \\
\hline Kogi & 984,710 & 863,989 & N/A & 561,782 & 421,328 & 521,016 \\
\hline Nasarawa & 397,008 & 729,266 & N/A & 694,527 & 511,547 & 580,778 \\
\hline Niger & 871,130 & 983,206 & N/A & $1,019,167$ & 813,671 & 851,937 \\
\hline Plateau & 672,442 & $1,050,370$ & N/A & $1,411,117$ & 982,388 & $1,034,853$ \\
\hline Rivers & $1,656,603$ & $2,160,133$ & N/A & $1,854,11$ & $1,565,461$ & 642,165 \\
\hline Taraba & 871,039 & 906,069 & N/A & 739,065 & 579,677 & 712,877 \\
\hline Yobe & 311,578 & 599,131 & N/A & 622,115 & 473,796 & 559,365 \\
\hline Total & $11,799,266$ & $15,139,474$ & & $11,955,539$ & $10,135,921$ & $9,264,605$ \\
\hline
\end{tabular}




\begin{tabular}{lllllll}
\hline Classsification & $\mathbf{1 9 9 9}$ & $\mathbf{2 0 0 3}$ & $\mathbf{2 0 0 7}$ & $\mathbf{2 0 1 1}$ & $\mathbf{2 0 1 5}$ & $\mathbf{2 0 1 9}$ \\
\hline E Mixed & & & & & & \\
\hline Adamawa & 845,107 & 955,847 & N/A & 907,706 & 636,018 & 811,534 \\
Bauchi & $1,176,542$ & $1,680,542$ & N/A & $1,610,094$ & $1,020,338$ & $1,024,307$ \\
FCT & 99,022 & 261,163 & N/A & 398,094 & 306,805 & 421,014 \\
Gombe & 844,539 & 976,136 & N/A & 770,019 & 460,599 & 554,203 \\
Kaduna & $1,676,029$ & $1,918,365$ & N/A & $2,569,963$ & $1,617,482$ & $1,663,603$ \\
Kebbi & 512,229 & 815,219 & N/A & 924,099 & 677,005 & 756,605 \\
Lagos & $1,751,981$ & $1,628,748$ & N/A & $1,945,044$ & $1,443,686$ & $1,089,567$ \\
\hline Total & $\mathbf{6 , 9 0 5 , 4 4 9}$ & $\mathbf{8 , 2 3 6 , 0 2 0}$ & & $\mathbf{9 , 1 2 5 , 0 1 9}$ & $\mathbf{6 , 1 6 1 , 9 3 3}$ & $\mathbf{6 , 3 2 0 , 8 3 3}$ \\
\hline Grand Total & $\mathbf{2 9 , 7 9 9 , 7 4 2}$ & $\mathbf{3 9 , 0 1 2 , 0 7 1}$ & & $\mathbf{3 6 , 5 4 2 , 3 1 4}$ & $\mathbf{2 8 , 5 8 7 , 5 6 4}$ & $\mathbf{2 5 , 3 2 1 , 6 4 6}$ \\
\hline
\end{tabular}

Source: Nigerian Independent National Electoral Commission

Tables 2 and 3 present an "embarrassment of riches" as it were. That is as it should be for any authentic statistical representation. Table 2 is of the raw figures of the various presidential elections while table 3 captures the percentages of the figures. The two tables are figures for the voter turn-outs for the elections. Those for 2007 are not available because the INEC did not disaggregate the votes according to the states of the federation as done with the results of all the other elections We should not however be carried away by the other facts of the statistics such as the fluctuation and/or decline in electoral figures of given regions. The Igbo region, the Yoruba region and the minority regions have all registered a decline in electoral turnout by their percentages. Curiously, the Hausa /Fulani have witnessed a steady growth in this regard. Only the mixed group has held a fairly steady (though slightly fluctuating) percentages of the voter turn-out. It is no place for us to hypothesize on what explains this though it might make an interesting matter for further analysis.

What remains of interest to us in this study is the fact that the so-called minorities as a group have always constituted a significant proportion the Nigerian population. This is what is even reflected in figures of the voter turn-out. It is the only group if combined with the mixed group has always added to more than $50 \%$ voter turn-out of the country.

Table 3. Distribution of votes according to ethnic classifications \%

\begin{tabular}{lllllll}
\hline Classification & $\mathbf{1 9 9 9}$ & $\mathbf{2 0 0 3}$ & $\mathbf{2 0 0 7}$ & $\mathbf{2 0 1 1}$ & $\mathbf{2 0 1 5}$ & $\mathbf{2 0 1 9}$ \\
\hline Hausa/Fulani & 11.3 & 17.50 & N/A & 19.99 & 21.73 & 21.97 \\
Igbo & 11.0 & 11.53 & N/A & 13.88 & 9.52 & 8.13 \\
Yoruba & 14.86 & 11.76 & N/A & 8.44 & 11.75 & 12.86 \\
Minority & 39.59 & 38.35 & N/A & 32.72 & 35.45 & 33.91 \\
Mixed & 23.17 & 20.86 & N/A & 24.97 & 21.55 & 23.13 \\
Total & $\mathbf{1 0 0}$ & $\mathbf{1 0 0}$ & N/A & $\mathbf{1 0 0}$ & $\mathbf{1 0 0}$ & $\mathbf{1 0 0}$ \\
\hline
\end{tabular}

(Additional Analysis)

\section{Looking Ahead}

If Nigeria must sincerely tackle her development problems, one of the ways must be to attend to the grievances of the minorities. These are numerous, they are natural and they are artificial. That Nigeria has such a multitude of ethnic nationalities is natural, but that the ethnic differences have been politicised is definitely artificial. Then there is the problem that ethnic politics has raised ethnic awareness to a point that renders the problems of ethnicity nearly insurmountable. The widespread sub-national agitations in Nigeria are a result of this level of ethnic awareness. With sufficient awareness each ethnic group has one grudge or other against the state or another group. But this is not to say we should give up on this. To solve a problem one must know and acknowledge the energies required to solve it. We acknowledge the difficulties in that spirit. These facts should help us contemplate the solutions.

To confront the problem of meeting minority demands Nigeria must engage social engineering. This means tinkering with the state structure. To renew how Nigerians relate with one another, the institutions of governance need to be reviewed. For example, Nigerian legislatures enjoy questionable privileges. There is no basis for making them permanent. Part-time legislative bodies should be far cheaper. There is no reason not to make them part-time. Closely related is the modality for representation, or recruitment to political positions. National electoral bodies, such as INEC, or state electoral bodies such as obtain now in Nigeria are misguided agencies. The one-size-fitsall approach is unhelpful. One date is declared for election into certain offices like the presidency, governorship, and legislative seats. Every cultural group is subjected to the same rules, not minding any cultural value orientation or variation. This arrangement should be reviewed to ensure that each ethnic group adopts their independent mode of selection or election. A constitutional provision should grant every nationality the number to be elected to public offices, such as the legislatures. Coupled with this, proportional representation should be incorporated and the winner-takes-all mode of election should be jettisoned. It might not be necessary to go the whole hog in adopting 
what Lijphat (1977) would describe as 'consociational democracy' because it too poignantly recommends elite dominance 'political corporation, of the segmental elites'. Its recognition and accommodation of segmental pluralism is quite appealing, on the other hand, however.

The essence of these recommendations is to rekindle the interest of the minorities. The new arrangement purports to shed off opportunism of public office, but instead to promote equity in group representation. In the end, the minority will breathe the air of accommodation and avail themselves for participation in public affairs. It is a sure way of recovering the energies of this large portion of the Nigeria population for national transformation described earlier as qualitative expansion in all spheres of life.

\section{Conclusion}

We have argued that all social groups need to be allowed participation in public affairs so as to harness their energies for development. Denial of rights is often the first step to blocking such participation and further dampening the enthusiasm of those affected. Even if they do not actively subvert efforts at any level towards development, their withdrawal or exclusion is sufficient to damage efforts at the national programme of development.

In Nigeria, the so-called minorities have not been properly accommodated. The colonial administrators started it all. Apart from attempting to segregate and suppress those they saw as ethnic minorities, they set enterprising ones against each other - the so - called divide and rule tactics. At independence the national leaders did not have the vision to dismantle these structures of discrimination among ethnic nationalities-what worked much against the interest of minorities as pawns on their political chess board, with the level of corruption in public office since SAP and the institution of political corruption in office. Since civil rule from 1999, things have worked dangerously to further isolate or exclude the minorities. But the minorities together constitute a population of Nigeria that cannot be ignored, if Nigeria hopes to achieve development. Bandying together against the majorities may be only reactionary. But the minorities should voice out for a review of the constitution to turn things around. They need this political space, not only for their own sakes, but also for that of the national project as well.

\section{References}

Bahsin, A.S (1997), Culture, National Integration and Democracy: An Indian Experience. In Nasidi, Y and Igoir, I (eds). Culture and Democracy, Nigeria: Ahmadu Bello Press Limited, 131-139.

Bernstein, H. (1973), Underdevelopment and Development: Third World Today, Harmondworth Penguin Books Ltd.

Crowder, M. (1978), The Story of Nigeria. London: Faber and Faber.

Ethnic Nationality Movement (ENM) (2014), Press Statement, issued February 2014, calling for Ethnic Nationalities Fraternal Conference in February, 2014. www.ethnicnationalitiesng.com

Kwanashie, M. (1997), Culture Pluralism and National Development: The Case for Nigeria. In Nasidi, Y. and Igoir, I. (eds), Culture and Democracy, Nigeria: Ahmadu Bello University Press Limited pp.244-253

Lijphart, A., (1977) Democracy in Plural Societies: A Comparative exploration. New Haven: Yale University Press.

Meredith, M. (1997), The State of Africa: A History of Fifty Years of Independence, London: Simon and Schuster UK Ltd.

Nkom, S.A (1997), Reflections on Culture and National Development in Nigeria, in Nasidi, Y. and Igoir (eds), Culture and Democracy, Nigeria: Ahmadu Bello University Press Ltd. 232-243.

Nnoli, O. (1980), Ethnic Politics in Nigeria, Enugu: Fourth Dimension Publishers.

Rodney, W. (1972, How Europe Underdeveloped Africa, London: Bogle- L’Ouverture Publications.

Utume, A. (2013), Analysis of the Challenge of Pluralism in Political Practice", in Benue Journal of Sociology, 4 (2), $75-95$

Utume, A and Shima, M.A., (2011), Age, Education and Political Participation: A study of the 2003 General Elections in Gboko and Katsina-Ala Local Government Areas of Benue State, in Africa Social Science, 1,1-17. Utume, A. (1994), Development or Delusion in Africa: Alternative Path to Development. A faculty Seminar Paper, Given on $3^{\text {rd }}$ April, 1996, Faculty of Social Science, Benue State University, Makurdi.

Utume, A. (2015), Persistence of African Heritage as an Alternative path to development. Academic Journal of Interdisciplinary Studies, 4 (1), 81-89.

Veirhelst, T.G (1990), No Life without Roots: Culture and Development, London: Zed Books Ltd.

Young, C. (1979), The Politics of Cultural Pluralism, Wisconsin: The University of Wisconsin Press. 